\title{
Entrevista com Jean-Yves Mérian
}

Esta entrevista com Jean-Yves Mérian, Professor Catedrático Emérito da Université de Rennes-2, concedida a Antonio Dimas e a Marcos Antonio de Moraes, em Paris, em novembro de 2013, dá ínicio a uma série de depoimentos de colegas, nacionais e estrangeiros, envolvidos com a Cultura Brasileira e com a sua transmissão crítica, em salas de aula e fora delas.

Com estes depoimentos, pautados pelo despojamento da fala, pretende-se um balanço múltiplo de experiências acadêmicas, que têm como ponto de partida comum a vivência pessoal e docente dos nossos entrevistados, cuja vinculação com o mosaico brasileiro nos rende avaliações de registro imprescindível.

Enquanto houvermos força e enquanto se sustentar este interesse pigmentado de reflexões alternativas, espelho, aliás, desta variedade brasileira, Teresa mantém sua disposição. Afinal, em suas origens, uma das remotas possibilidades etimológicas do nome escolhido para esta revista da Literatura Brasileira da USP/FFLCH é o de colheita. Não é outro, pois, o objetivo desta iniciativa.

Depois de se formar em Português, Espanhol e Inglês na Universidade de Rennes, em 1967, Jean-Yves Mérian começou sua carreira acadêmica na mesma universidade, a convite de Jean-Michel Massa, seu futuro orientador.

Em duas oportunidades, no entanto, Jean-Yves afastou-se da docência. Entre 1970 e 1971, quando se tornou Diretor da Aliança 
Francesa de Santa Cruz de la Sierra, na Bolívia. Entre 1985 e 1998, quando prestou serviços culturais junto aos serviços diplomáticos franceses em Buenos Aires, Lisboa e São Paulo.

Seu doutoramento, em torno da vida e obra de Aluísio Azevedo, ocorreu em 1980. Desde então, suas pesquisas ampliaram-se, desdobraram-se em vários artigos e têm-se voltado para tópicos como Literatura Afro-brasileira; Ideologias no Brasil nos séculos XIX e Xx; A construção de uma identidade e de uma cultura nacionais; A evolução das relações culturais entre o Brasil e seus países vizinhos nos séculos XIX e Xx; Literatura Brasileira contemporânea.

Em 2013, saiu pela Garamond/Biblioteca Nacional, a segunda edição de seu Aluísio Azevedo, vida e obra.

Como foi, Jean-Yves, que começou seu interesse intelectual pelo universo literário brasileiro? Em que altura da sua formação escolar? Quem lhe acenou com esse caminho?

Quando iniciei meus estudos universitários na Universidade de Rennes, em 1962, não tinha nenhum conhecimento da língua portuguesa, que não era ensinada nos liceus franceses. Já tinha um bom conhecimento do espanhol e comecei a minha Licence de espanhol.

Não tinha então o projeto de ser professor. Minha intenção era aprofundar os meus conhecimentos de espanhol, inglês e russo, línguas que eu tinha estudado no secundário, assim como de história para - num segundo tempo - estudar ciências políticas. Porém, desde a adolescência, tinha uma verdadeira paixão pela América Latina.

Comecei a estudar a língua portuguesa para poder abordar de forma mais eficiente o estudo da história e da cultura brasileira, o que não me permitia o conhecimento da língua espanhola.

Devo lembrar que no começo dos anos 1960, depois da Revolução Cubana de janeiro de 1959, muitos jovens manifestaram grande interesse pela América Latina. Na Universidade de Rennes já existia um pequeno departamento de português, criado em 1921, um ano depois do centro da Sorbonne, em Paris.

Os estudantes, na sua grande maioria, viam na língua portuguesa um complemento dos estudos hispânicos. O estudo da língua, de norma portuguesa, com algumas noções das "particularidades” brasileiras, constituía o essencial das aulas.

Só no terceiro ano é que se estudava literatura portuguesa e algumas noções de literatura brasileira. Porém, o departamento de português de Rennes era dirigido por 
Jean-Michel Massa, que preparava uma tese sobre Machado de Assis e que, ao contrário de professores de outras universidades, incentivava os estudantes a lerem e a estudarem obras de autores brasileiros.

O predecessor de Jean-Michel Massa tinha sido Georges Boisvert, que mais tarde seria professor em Poitiers e na Sorbonne. Embora especialista de literatura portuguesa, o professor Boisvert realizaria vários estudos e notáveis traduções dos romances de Jorge Amado.

\section{Mas além do prof. Massa e do prof. Boisvert, Rennes tinha alguma outra ligação anterior com o Brasil?}

Na Universidade de Rennes, as relações com o Brasil eram antigas e sólidas, graças à presença do sociólogo Paul Arbousse Bastide, que tinha sido membro da "Missão Francesa" de São Paulo até 1946; do professor de filosofia Gilles Gaston Granger, que lecionou na usp depois dele; e do professor de geografia Francis Ruellan, que passou mais de dez anos no Rio de Janeiro até meados dos anos 1950.

Esses professores, famosos no Brasil, não tinham muito contato com o departamento de português. A interdisciplinaridade não existia na época. Tudo mudou a partir de 1968. A nova política universitária fez com que a Sorbonne fosse dividida em dez universidades. Foi quando o ensino do português tirou proveito da abertura de novos centros de ensino e de pesquisa e da diversificação do ensino das línguas estrangeiras nas universidades.

Porém, só dois departamentos se emanciparam da tutela dos hispanistas: Rennes e Toulouse. Nas novas universidades de Paris - Sorbonne, Sorbonne Nouvelle, Vincennes (hoje Saint Denis), Paris-1o Nanterre -, o português era apenas uma seção dos Departamentos de Estudos Ibero-americanos, com uma autonomia limitada. E dentro dessas seções a presença lusitana era numericamente muito mais importante que a brasileira. Isto se explica pelo fato de que a maioria dos professores tinham sido anteriormente professores de espanhol e também pelo apoio do governo português, sempre muito mais ativo que o brasileiro.

No entanto, o ensino do português foi se desenvolvendo na década de 1970, com criações de novos postos de professores catedráticos e de professores assistentes em Lille, Lyon, Grenoble, Montpellier, Aix-en-Provence, Bordeaux, Limoges, Clermont Ferrand, Nantes, Nice. Leitores portugueses e brasileiros davam aulas de iniciação em todas as universidades onde existia o ensino do espanhol. 
A inexistência de concursos para professores de português nos colégios e liceus franceses tornava muito improvável o crescimento do número de estudantes dispostos a se especializarem em estudos luso-brasileiros. Ninguém se dispõe a fazer uma graduação e menos ainda um doutorado, quando a única perspectiva é o desemprego. No começo dos anos 1970, o número de diplomados em português não chegava a trinta na França inteira.

A criação dos concursos de recrutamento de professores - CAPES, em 1973, e Agrégation, em 1974 - para ensinar nos colégios e liceus, principalmente na região de Paris e nas cidades onde passou a residir uma população de origem portuguesa de mais de 700 mil pessoas, mudou totalmente as perspectivas.

O número de estudantes de português cresceu de forma notável nas universidades que tinham departamentos organizados, passando dos duzentos alunos a cada ano entre $1980 \mathrm{e}$ 200o. Em vinte anos, o número de professores do secundário chegou a mais de quatrocentos.

Estas estatísticas merecem um comentário: a maioria dos professores, estudantes universitários e alunos dos colégios e liceus eram "luso-descendentes". O ensino do português de Portugal era dominante e era difícil abrir um espaço satisfatório para a língua de norma brasileira e para o ensino da literatura e civilização brasileiras.

\section{Mas essa tensão entre o português de Portugal e o do Brasil ajudou ou prejudicou o ensino da lusofonia?}

Essa realidade concreta não impediu que os estudos brasileiros se desenvolvessem nas universidades, porque nos concursos a literatura e a civilização brasileiras tinham nas provas o mesmo peso que os estudos portugueses.

Aliás, com a independência dos países africanos de língua portuguesa, após a descolonização em 1975, abriu-se também um espaço para a literatura e a civilização desses países, nos programas dos concursos de recrutamento dos professores. As demais universidades seguiram o rumo traçado por Rennes e Paris-8 em 1968, recrutando professores dispostos a trabalhar sobre escritores angolanos, moçambicanos e cabo-verdianos.

Esse era, em síntese, o panorama dos estudos luso-brasileiros, durante a minha formação, quer antes de 1968, quer nos anos imediatamente seguintes.

\section{E onde você se insere nesse percurso tão bem traçado?}

Em 1968, apesar da incerteza sobre o futuro do ensino do português na França, aceitei 
o convite de Jean-Michel Massa para ensinar a língua e civilização portuguesas, paralelamente às minhas funções de professor de espanhol num liceu.

Decidi também empreender uma tese de Doutorado de Estado sob a orientação de Jean-Michel Massa. Meu interesse pelo Brasil e, no plano literário, meu particular apreço por Émile Zola e pelo Naturalismo na França e nos países de língua espanhola me levaram a escolher trabalhar sobre o Naturalismo no Brasil e sobre a vida e a obra de Aluísio Azevedo.

Benedito Nunes, então professor convidado na Universidade de Rennes, com quem muito aprendi, me incentivou e me deu interessantes pistas de trabalho.

Tive que interromper as minhas pesquisas durante os anos 1970 e 1971, pois, em lugar do serviço militar, fui fazer um serviço civil, dirigindo a Aliança Francesa de Santa Cruz de la Sierra, na Bolívia.

Não foi uma interrupção total, porque descobri o Brasil no começo de janeiro de 1971, chegando de Santa Cruz a Corumbá pelo famoso "trem da morte". Aliás, continuei a viagem de trem: Campo Grande, Bauru, São Paulo até chegar à Central do Brasil, no Rio de Janeiro. Outros tempos...

Mas que melhor modo de descobrir um Brasil, fora dos clichês que formavam o imaginário francês dos jovens da minha geração? Senti a presença da ditadura militar logo na chegada a Corumbá. Os cartazes denunciando os "subversivos e terroristas" ocupavam muitas paredes nas estações e espaços públicos. A polícia militar era onipresente. Mesmo vindo da conturbada Bolívia, o ambiente era realmente assustador.

\section{E o seu primeiro Brasil começou por onde?}

No Rio de Janeiro. A minha primeira temporada de um mês no Rio de Janeiro foi muito proveitosa. Graças aos contatos de Jean-Michel Massa, entrei em relação com pessoas que me deram bons conselhos e orientações. Foi o caso de Alexandre Eulálio, de Paulo Rónai e do maravilhoso bibliófilo Plínio Doyle, que tão generosamente me abriria, durante anos seguidos, as portas da sua biblioteca, onde encontrei revistas, jornais e documentos manuscritos que Plínio - o dr. Plínio, como era conhecido - me deixava fotografar.

Pude contar também com o apoio total de Aluísio Azevedo Sobrinho, filho caçula de Artur Azevedo, grande colecionador de tudo o que dizia respeito ao pai e ao tio. Graças à relação de confiança e de amizade com os dois, consegui juntar, a partir do ano seguinte, uma valiosa documentação que não conseguiria na Biblioteca Nacional.

Na Academia Brasileira de Letras comecei a pesquisar nos arquivos e na biblioteca. Encontrei Josué Montello, que, apesar de se considerar, como maranhense que era, 
dono de Aluísio Azevedo, me deu algumas dicas sobre o paradeiro de certos documentos e livros, como a edição de 1881 de $O$ mulato.

Comecei também, em janeiro de 1971, a frequentar os sebos, alguns deles hoje desaparecidos, como a Livraria São José, para constituir a minha própria biblioteca de obras de Aluísio Azevedo, e obras críticas sobre o autor e sobre a vida literária dos últimos trinta anos do século xIx. Era um prelúdio indispensável, já que não os encontraria na França, e ainda menos na Bolívia, onde residia então.

Durante essa primeira temporada no Brasil, consegui também localizar na Biblioteca Nacional os jornais e as revistas que seriam a minha principal fonte de informação sobre o ambiente político, social, cultural do Rio de Janeiro. Foi nessa biblioteca abafada, naquele distante e úmido verão carioca, que encontrei um jovem pesquisador paulista que trabalhava sobre as crônicas de Olavo Bilac. Era o Antonio Dimas, com quem iniciei uma bela e longa amizade.

\section{Essa pesquisa recebia financiamento de algum órgão público ou era do próprio bolso?} Naquela época não existiam, como hoje, relações formais entre universidades francesas e universidades brasileiras. Tampouco existiam mecanismos públicos de apoio à pesquisa, co-orientação de teses... No plano acadêmico tudo dependia das relações que cada pesquisador conseguia estabelecer com pesquisadores do país onde realizava o seu trabalho. Depois de um ano de intensas e variadas atividades na Bolívia, que me deixaram pouco tempo para atividades acadêmicas, voltei à França. Foi só aí, então, que consegui aproveitar o material que tinha reunido e comprado no Rio de Janeiro, em janeiro de 1971.

O meu interesse pela vida e a obra de Aluísio Azevedo se confirmou. Ele me pareceu ser o autor mais representativo de uma geração de escritores que lutou para construir uma literatura nacional, num país onde pouco se lia, e onde os escritores não tinham estatuto nem direitos, e onde ninguém podia viver das Letras. Pareceu-me importante estudar a condição do escritor, as relações no meio intelectual e cultural do tempo, para entender o papel dos romancistas, como pintores da sociedade e como formadores de opinião. Aluísio Azevedo, como escritor realista-naturalista confesso, era a pessoa indicada para as minhas interrogações, já que ele sempre assumiu posições republicanas, abolicionistas, anticlericais e laicas.

Queria entender também, no caso de Aluísio Azevedo, as relações que podiam existir entre a produção de romances folhetins e os romances realistas, assim como o 
papel dos jornais na difusão da literatura. Eu considerava que, para entender a obra de Aluísio Azevedo, era necessário conhecer o melhor possível sua vida, suas origens, sua formação no meio patriarcal e escravocrata do Maranhão e depois o contexto da sua produção no Rio de Janeiro.

Eu não tinha a pretensão de descobrir a Lua, mas achei estranha a similitude entre estudos publicados por biógrafos e críticos consagrados, que se repetiam uns aos outros, dando a sensação de não ter sido feita nenhuma pesquisa nova.

Não será demais lembrar que nos anos 1970-80 não existia nenhum dos meios informáticos que hoje tanto facilitam o trabalho do pesquisador. Nenhum jornal, nenhuma revista digitalizada. Em muitos casos as bibliotecas não dispunham sequer de xerox, nem de serviço de microfilme. Não existindo máquina fotográfica digital, era preciso utilizar máquina fotográfica com filmes de muito contraste, com tripé, com luz natural. Além de lento, era um processo muito caro.

Acho útil lembrar essas condições de trabalho para entender a demora das pesquisas que realizei para redigir o livro. Durante sete anos, em períodos de um a dois meses, pesquisei nas bibliotecas e arquivos públicos do Rio de Janeiro, Recife, São Luís do Maranhão, São Paulo, Buenos Aires, Lisboa, Paris. Como indiquei previamente, Plínio Doyle, Aluísio Azevedo Sobrinho, Josué Montello, no Rio de Janeiro, e Pastor Azevedo Lúquez, herdeiro de Aluísio Azevedo, em Buenos Aires (com muitas reticências), puseram à minha disposição cartas, livros, manuscritos, jornais e livros que não existiam nas bibliotecas. Infelizmente, os acervos únicos de Aluísio Azevedo Sobrinho e de Pastor Azevedo Lúquez foram dispersados ou vendidos depois da morte de ambos. Porém, o acervo de Plínio Doyle está conservado na Casa de Rui Barbosa, no Rio de Janeiro.

Não tendo nenhum financiamento de organismos públicos franceses ou brasileiros, precisei assumir os gastos com meu próprio bolso. Porém, paralelamente às funções de professor e pesquisador, dediquei-me à organização de viagens de grupos de franceses que queriam descobrir o Brasil, numa organização chamada Nouvelles Frontières. Abri até os primeiros circuitos de "viagens de descoberta" através da Amazônia e formei uns dez acompanhantes para os diferentes tipos de viagem. Esta atividade me permitiu financiar várias viagens de pesquisa para a tese, entre 1973 e 1980.

\section{Como eram as condições dessas bibliotecas, então?}

$\mathrm{Na}$ época das minhas pesquisas, as bibliotecas não dispunham, como hoje, de sistemas de climatização, e durante o verão as janelas abertas deixavam entrar vento e poluição. 
Os livros eram relativamente bem conservados, apesar das traças e do cupim. Não era o caso dos manuscritos, muitas vezes carcomidos, e dos jornais e revistas, que em certos casos viravam farelo, apesar do grande cuidado no manuseio. Eu tinha a estranha sensação de ser o último leitor de certos números de jornais diários.

Hoje a situação mudou totalmente, e o que podia ser salvo foi microfilmado e está sendo digitalizado, felizmente; não só no Rio de Janeiro mas também na Biblioteca de São Luís, totalmente renovada e com equipamento de última geração. Outros tempos!!! Quem me dera ter tido essas condições de trabalho e ter podido acessar por internet documentos que precisei garimpar na poeira e no calor. Mas no fim dos anos 1970, quem imaginava que tudo isso existiria?

\section{Nessas bibliotecas, então, quais eram suas prioridades? Era pesquisa bibliográfica ou documental, de fonte primária?}

No contexto difícil da década 1970-80, consultei todos os jornais e revistas de São Luís do Maranhão entre 1870 e 1882 e todos os jornais e revistas do Rio de Janeiro entre 1876 (primeira viagem do escritor à capital) e 1898, um pouco após a mudança de vida do romancista.

Procurei nos arquivos diplomáticos em Paris, Lisboa, Rio de Janeiro, os documentos necessários para completar as informações sobre o contexto social e político de São Luís do Maranhão e do Rio de Janeiro, assim como sobre a atuação do pai de Aluísio Azevedo, e do próprio romancista, quando exerceu a função de cônsul do Brasil no estrangeiro. Enfim, estudei as correspondências disponíveis nos acervos de Aluísio Azevedo Sobrinho, de Pastor Azevedo Lúquez e nos arquivos da Academia Brasileira de Letras.

A partir dessas pesquisas, reuni um corpus variado e extenso tanto sobre o contexto social, cultural e político, como sobre a vida e a obra de Aluísio Azevedo.

Esse material de pesquisa foi essencial para construir o meu estudo: entender a influência da vida do escritor na realização da sua obra, as razões que o levaram a publicar paralelamente romances realistas e romances folhetins, a interação entre as duas formas de escrever. Essa documentação me permitiu também avaliar melhor os compromissos ideológicos e estéticos do romancista como escritor e como jornalista.

A pesquisa, justificada pelo projeto de tese de doutorado, foi muito útil para os meus conhecimentos sobre o Brasil do fim do Império e primeiros anos da República e me permitiu orientar várias pesquisas sobre temas relacionados com a vida cultural e literária daquela época. 


\section{Como você vê e via a fortuna crítica de Aluísio?}

A fortuna crítica de Aluísio Azevedo foi bastante escassa até o fim do século xx, porém nos últimos anos surgiram vários estudos valiosos sobre a obra em folhetim do romancista e boas edições críticas de $O$ cortiço, por exemplo. Existe um grande contraste entre o grande número de edições dos principais romances do escritor maranhense, devido em particular à inclusão dessas obras nos programas de vestibular, e o interesse limitado que o autor desperta entre os críticos e professores universitários.

Atualmente estou reunindo cartas e textos inéditos de Aluísio Azevedo, que espero publicar até o fim de 2014. Esses textos, de conteúdo às vezes polêmico, revelam facetas interessantes da personalidade do escritor. Outro trabalho em curso é uma edição crítica de $O$ mulato, que permitirá apreciar a evolução das concepções estéticas de Aluísio Azevedo a partir do confronto entre dois manuscritos existentes e a primeira edição, que é de 1881. A edição utilizada por todas as editoras desde o fim do século xıx até hoje é a de 1889. Ora, esta de 1889 é muito diferente do texto original de 1881, como demonstro no meu livro Aluísio Azevedo vida e obra, publicado em 1988 e cuja segunda edição acabou

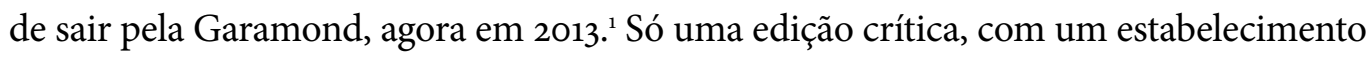
sério do texto, ajudará a entender a transição entre romantismo e realismo-naturalismo no Brasil do começo dos anos 1880 . Tenho outro trabalho em andamento, fora desse âmbito, sobre as relações franco-brasileiras na Amazônia no fim do século XIX.

Você gostaria de falar um pouco sobre a repercussão crítica dessa biografia, Jean-Yves? É sempre difícil responder a esse tipo de perguntas, pois não li tudo o que saiu a propósito do livro. Porém, posso afirmar que tanto O Globo quanto os jornais do Maranhão e Zero Hora de Porto Alegre deram uma ótima cobertura por ocasião do lançamento da nova edição do livro. Muitas páginas na internet também foram a ele consagradas.

\section{Mudando um pouco o rumo, Jean-Yves: Como está o português, hoje em dia, na escola média francesa? Tem presença marcante?}

Hoje em dia a presença do ensino do português na escola média francesa é preocu-

1. Cf. mérian, Jean-Yves. Aluísio Azevedo: vida e obra (1857-1913). 2. ed. Trad. Claudia Poncioni. Rio de Janeiro: Fundação Biblioteca Nacional; Garamond, 2013. 
pante. Na França, o desenvolvimento do ensino da língua portuguesa foi fruto de uma decisão política, de diversificação do ensino das línguas estrangeiras nos colégios e liceus, a partir de 1973. Foi também o fruto de uma ação militante muito forte da ADEPBA, a Associação para o Desenvolvimento dos Estudos Portugueses, Brasileiros e da África lusófona. Esta associação, que presidi em diversas oportunidades, foi muito ativa até 2004. Em 1984, organizei com minha amiga Solange Parvaux, inspetora-geral de Português no Ministério francês da Educação, as "Assises nationales du portugais en France". Esse encontro reuniu mais de duzentos participantes, entre professores, pesquisadores e representantes do mundo econômico, político e social. Foi um encontro que teve impacto importante para o desenvolvimento do ensino do Português. Isso foi prolongado entre 1986 e 1988, com a organização das "Années France-Brésil". Nessa altura, eu já tinha dado início ao período durante o qual passei catorze anos afastado da universidade, destacado junto ao Ministère de la Culture da França e ao Ministère des Affaires étrangères, como conselheiro cultural em Buenos Aires, Lisboa e São Paulo.

No final do século xx, o número de professores formados e concursados ultrapassava o número de quatrocentos. Depois disso, a situação mudou totalmente. A partir de 2002 e de 2004 para cá não existe mais concurso para professor de português do secundário.

Os professores aposentados não são substituídos e, em muitos casos, os cursos estão sendo fechados. As estatísticas oficiais são enganosas, porque incluem alunos inscritos em cursos financiados pelo governo português e porque não indicam que $o$ único crescimento diz respeito aos alunos do departamento da Guiana Francesa, que representa um caso à parte. Este crescimento não compensa o declínio do ensino na França metropolitana.

Se não houver uma mudança na política do ensino das línguas estrangeiras, e, no caso do português, o restabelecimento dos concursos de recrutamento, a presença da língua portuguesa no meio escolar francês será muito marginal. 


\section{No ensino superior também?}

As consequências são graves para o ensino universitário. É cada vez mais difícil encontrar estudantes dispostos a dedicar cinco anos da sua vida fazendo uma graduação e um mestrado de língua, literatura e civilização portuguesa, brasileira e africana, sem nenhuma perspectiva de trabalho como professor.

Com exceção da Sorbonne Nouvelle-Paris 3 e em menor medida de três ou quatro outras universidades, muitos departamentos de português encontram-se com um número insignificante de alunos, a não ser os que estudam a língua portuguesa como complemento de outra formação universitária.

As universidades, em consequência desta situação, suprimiram postos de professores ou não os renovaram quando os titulares se aposentaram. Os cursos clássicos estão se fechando em quase todas as universidades. A única estratégia para limitar esta decadência é a promoção de formações pluridisciplinares ou formações do tipo LEA (Langues Étrangères Appliquées), nas quais o português representa, com outra língua estrangeira, uma componente da formação que inclui direito, economia, gestão... Existem também, em poucas universidades, graduações com um perfil profissionalizante. Em todos os casos, porém, os estudos literários estão gravemente ameaçados.

\section{E o quê a nova geração de brasilianistas franceses poderia fazer neste sentido?}

A única forma, nesta época de recessão econômica e na ausência de concursos de recrutamento para professores do secundário, é procurar juntar forças entre os brasilianistas - cada vez menos numerosos - e organizar estratégias de formações pluridisplinares, já que formações puramente ligadas às artes e às letras estão muito comprometidas. A cooperação com universidades brasileiras, para programas de pesquisa e de formação de jovens pesquisadores, será também indispensável.

Contrariamente ao que se passava nas décadas anteriores, o governo brasileiro parece agora empenhado em contribuir para a difusão do ensino da língua, da literatura e da civilização brasileiras no exterior. Isto pode ajudar dando tempo ao tempo, até que os intercâmbios econômicos e comerciais entre o Brasil e a França conheçam um desenvolvimento mais importante que possa suscitar um interesse maior pelos estudos brasileiros, entre estudantes oriundos de diversas formações acadêmicas. 